\title{
Review Article \\ Clinical and Pathological Implications of Concurrent Autoimmune Thyroid Disorders and Papillary Thyroid Cancer
}

\author{
L. L. Cunha, ${ }^{1}$ R. C. Ferreira, ${ }^{1}$ M. A. Marcello, ${ }^{1}$ J. Vassallo, ${ }^{2}$ and L. S. Ward ${ }^{1}$ \\ ${ }^{1}$ Laboratory of Cancer Molecular Genetics, Faculty of Medical Sciences, University of Campinas (FCM-Unicamp), \\ 126 Tessalia Vieira de Camargo St., Cidade Universitária, Barão Geraldo, Campinas, 13083-970 São Paulo, SP, Brazil \\ ${ }^{2}$ Laboratory of Molecular Pathology, Ciped, Faculty of Medical Sciences, University of Campinas (Unicamp), \\ 126 Tessalia Vieira de Camargo St., Cidade Universitária, Barão Geraldo, Campinas, 13083-970, São Paulo, SP, Brazil
}

Correspondence should be addressed to L. S. Ward, ward@unicamp.br

Received 29 August 2010; Revised 26 October 2010; Accepted 16 December 2010

Academic Editor: Gary L. Francis

Copyright $\odot 2011$ L. L. Cunha et al. This is an open access article distributed under the Creative Commons Attribution License, which permits unrestricted use, distribution, and reproduction in any medium, provided the original work is properly cited.

\begin{abstract}
Cooccurrences of chronic lymphocytic thyroiditis (CLT) and thyroid cancer (DTC) have been repeatedly reported. Both CLT and DTC, mainly papillary thyroid carcinoma (PTC), share some epidemiological and molecular features. In fact, thyroid lymphocytic inflammatory reaction has been observed in association with PTC at variable frequency, although the precise relationship between the two diseases is still debated. It also remains a matter of debate whether the association with a CLT or even an autoimmune disorder could influence the prognosis of PTC. A better understanding about clinical implications of autoimmunity in concurrent thyroid cancer could raise new insights of thyroid cancer immunotherapy. In addition, elucidating the molecular mechanisms involved in autoimmune disease and concurrent cancer allowed us to identify new therapeutic strategies against thyroid cancer. The objective of this article was to review recent literature on the association of these disorders and its potential significance.
\end{abstract}

\section{Introduction}

Thyroid cancer is the most common endocrine malignancy and was considered responsible for 1600 deaths amongst 300,000 patients diagnosed with the disease in the USA in 2009 [1]. The incidence of differentiated thyroid cancer (DTC) in the United States and worldwide continues to increase, having more than doubled over the past three decades $[2,3]$. A similar trend has been observed in other countries across Europe, Asia, Oceania, and South America [4]. In fact, only a few countries have reported a decline in thyroid cancer incidence: Sweden (18\% reduction for both men and women), Norway (5.8\% reduction for women), and Spain (25.9\% reduction for women) [4]. The disease incidence is increasing in other European countries, such as Switzerland (5.3\%) and France (155.6\%) [4]. A common aspect in all epidemiological reports is that the highest rate of increase is for small and localized thyroid cancers, which probably contributes to the stable and relatively low mortality observed. However, there are several lines of evidence indicating that the increased incidence of DTC is also related to other factors, including the increasing amount of large tumors that would certainly be detected without the need for more sophisticated or sensitive imaging methods and a parallel increase of exposure to a series of environmental factors associated with cancer, such as exposure to radiation [5, 6]; living in volcanic areas [7]; iodine intake $[8,9]$; female gender [10], which might be related to estrogen, a subject that is being studied for our group; obesity [11]; and genetic factors that might be related to susceptibility to DTC [12-17].

A parallel increase has been observed in the incidence of autoimmune thyroid diseases, such as thyroiditis. Chronic lymphocytic thyroiditis (CLT) and DTC, mainly PTC, share some epidemiological features, such as the relationship with ionizing radiation exposure $[6,18]$ and dietary iodine $[19$, 20]; both also share some molecular features [21-28] and are more likely to occur in women than in men [29-31]. 
Although most tumors originate from follicular cells, they present remarkably different features. In addition, likewise breast, prostate, and other human neoplasias, microscopic thyroid tumors are frequently found at autopsies and in surgical specimens [32]. However, the impact of the immune system, the presence of autoimmune thyroid diseases, and their relationship with cancer development is a matter of controversy [4]. Also, literature repeatedly reports association between CLT and thyroid cancer. Geographically widespread association and incidence of CLT with thyroid cancers are shown on Table 1.

\section{Concurrent Chronic Lymphocytic Thyroiditis (CLT), Thyroid Autoimmune Diseases, and Differentiated Thyroid Carcinomas (DTC)}

Hashimoto's disease and Graves' disease are the two most common forms of autoimmune thyroiditis (AT), the archetypal organ-specific autoimmune disease in humans. Both are characterized by lymphocytic infiltrate and autoreactivity against thyroid autoantigens [43-45].

Chronic lymphocytic thyroiditis (CLT) is an autoimmune disease characterized by widespread lymphocyte infiltration, fibrosis, and parenchymal atrophy of thyroid tissue. Hashimoto's thyroiditis (HT) is characterized by infiltration of the thyroid gland by inflammatory cells, often followed by hypothyroidism due to destruction and eventual fibrous replacement of the parenchymal tissue. In HT, the body also produces autoantibodies to thyroid-specific antigens (Figure 1), considering that thyroglobulin ( $\mathrm{Tg}$ ) and thyroperoxidase (TPO) are the two primary antigens in AT [46-48]. HT is characterized by a gradual loss of thyroid function, goiter, and T-cell infiltration in histology, affecting women more often than men, with a sex ratio of $7: 1$, and occurring in genetically susceptible populations, but lacking a strong association with HLA. The overriding feature of HT is the progressive depletion of thyroid epithelial cells, which are gradually replaced by mononuclear cell infiltration and fibrosis $[47,49,50]$. In thyroiditis, especially HT, parenchyma of thyroid gland is progressively lost and replaced by cells of the inflammatory infiltrate that produce chemokines, cytokines, and growth factors, most of which are under NF- $\beta$ transcriptional control. The persistent stimulation of residual thyrocytes with such molecules could induce the activation of NF- $\beta$ in follicular cells, thereby creating a functional network between thyroid epithelial cells and inflammatory cells [49].

In a number of human malignancies, the presence of lymphocytic infiltration in or around a tumor is commonly viewed as representing a host immune response [52]. Although the presence of tumor-associated lymphocytic infiltration is widely regarded as representing a host immune response, the impact of this inflammatory response on tumor behavior may be variable [28, 53-55]. In addition to the common occurrence of CLT and papillary thyroid carcinomas (PTC), it has been suggested that the relatively high prevalence of apparently indolent PTC in an autopsy series may represent host immune control [56].
The relationship between CLT and PTC was first proposed by Dailey et al. in 1955 [21]. Since this initial description, the association between the diseases has been repeatedly reported and highly debated in the literature, remaining controversial.

A thyroid lymphocytic inflammatory reaction has been observed in association with PTC at variable frequency, ranging from $0.5 \%$ to $58 \%[21-28,34,37,39,40,57,58]$. This wide distribution of coexisting CLT and PTC reported in a number of studies may be due, at least in part, to differences in the level of histological examination and criteria of autoimmunity characterization, patient selection or indications for thyroidectomy, environmental factors (history of radiation exposure) [59], genetic or population background [57], and geographic factors (e.g., the amount of iodine intake) [59-61].

Thyroid autoimmunity is a broad spectrum disease also manifested as the presence of antithyroid antibody (ATA). A series of reports indicate a close association between ATA and malignancy [50,62], while others are not able to confirm this association [63-66]. Boi et al. assessed ultrasound- (US-) guided fine-needle aspiration cytology obtained from 590 unselected consecutive patients with single thyroid nodules and positive or negative serum antithyroid antibody. Cytological results were divided into three classes of increased risk of malignancy: low risk or benign, indeterminate risk, and suspect or malignant. They suggested that the presence of antithyroid antibodies confers an increased risk of suspicious or malignant cytology in unselected thyroid nodules [62]; even this result is not confirmed in other reports $[67,68]$.

There are reports in the literature on the relationship between other thyroid autoimmune diseases, such as Graves's disease and thyroid cancer. Some studies have suggested a high incidence of malignant thyroid nodules in patients with Graves' disease and hyperthyroidism, and that thyroid cancer behaves more aggressively when associated with Graves' disease, although still controversial [69-72]. As TSH stimulates growth of metastatic differentiated thyroid cancer expressing the TSH receptor (TSHR), it is possible to hypothesize that high levels of anti-TSHR antibodies of Graves' patients might stimulate thyroid cancer growth and early metastatic spread, thus negatively affecting patient outcome, as reviewed by Belfiore et al. [73]. However, other studies do not support the suggestions that thyroid cancer in patients with Graves' disease is more aggressive than in either patients with toxic nodular goiter or euthyroid subjects, suggesting that concurrent Graves disease is not a good prognosticator $[74,75]$.

Even in reduced frequency, CLT is also presented in association with follicular thyroid carcinoma (FTC). Loh et al. [37] studied subjects with lymphocytic thyroiditis (LT), including Hashimoto's thyroiditis and cell lymphocytic infiltrates around thyroid neoplasms. Lymphocytic thyroiditis (LT) was recorded in 125 of 564 patients (22\%) with PTC histology, when comparing with three of 67 patients $(4.5 \%)$ with follicular or Hürthle cell histology. They found that patients with LT almost uniformly had PTC, consistent with the observation by other investigators $[33,34,76,77]$. In fact, Souza et al. [38] reported that TPO 


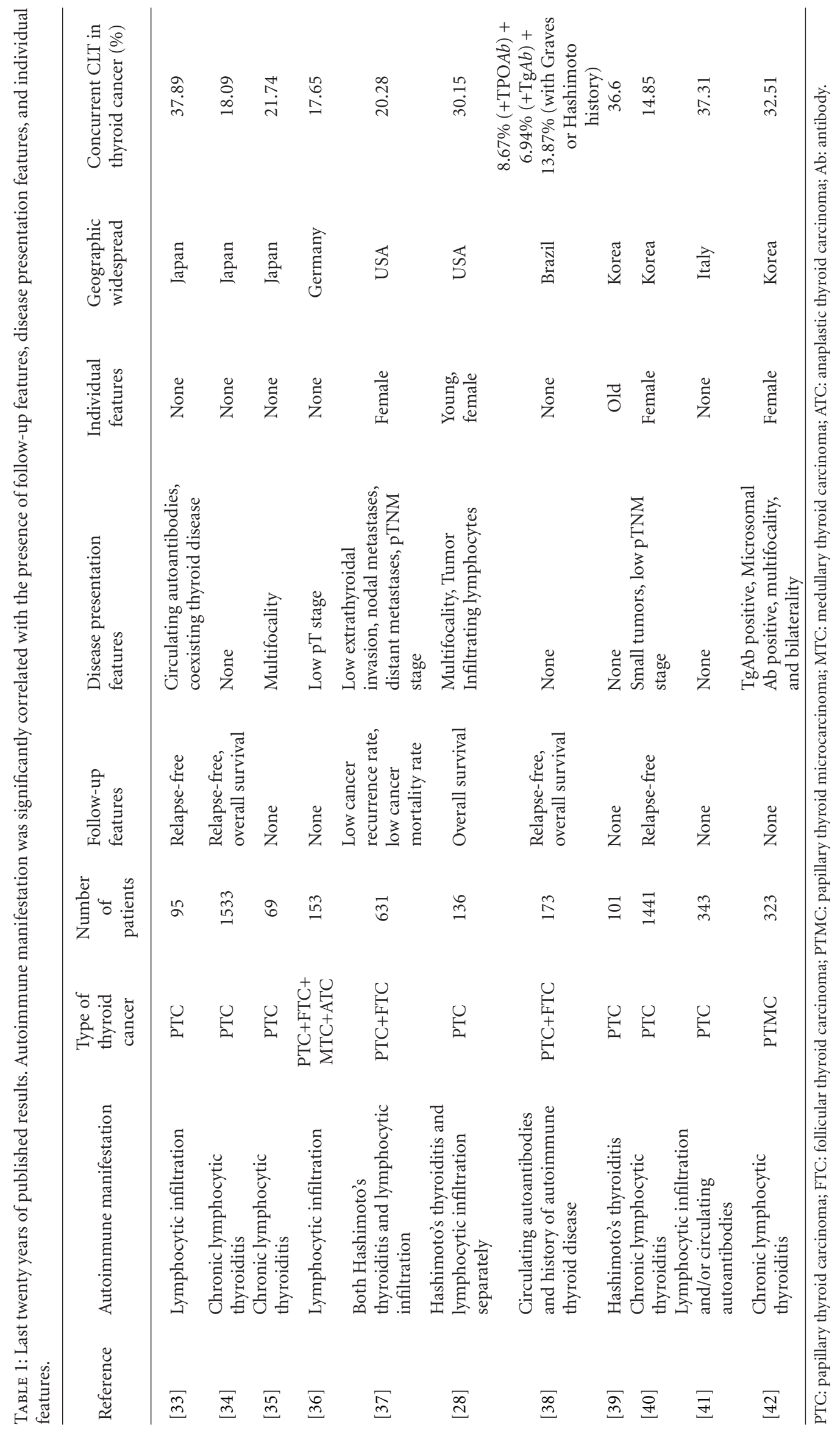




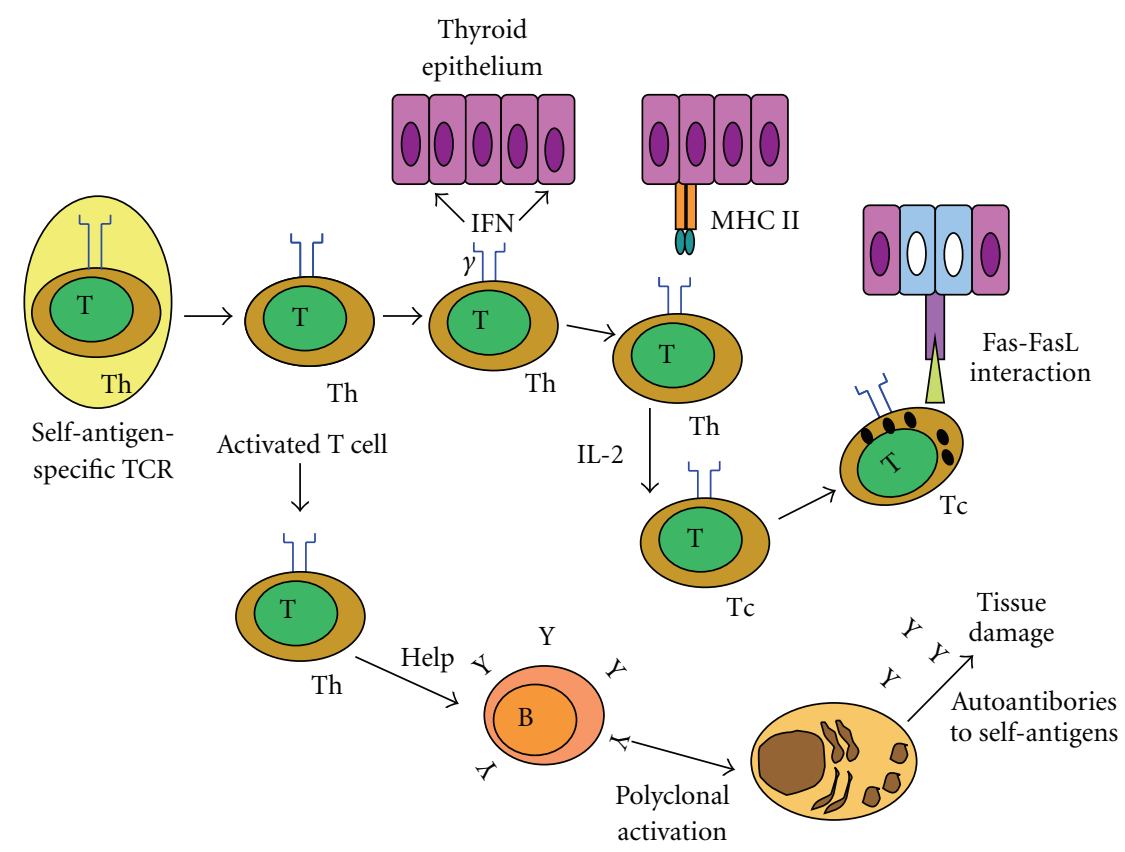

FIGURE 1: Activation of a self-specific T-cell initiates a cascade of events that amplifies the immune response and involves both CD4 and CD8 $\mathrm{T}$ cells, inducing an antibody-mediated response. B: B cells; IFN- $\gamma$ : interferon- $\gamma$; IL-2: interleukin-2; MHCII: major histocompatibility class II; T: T cells; Tc: cytotoxic T-cell; Th: T helper cell (adapted from [51]).

antibody was present in 14 of 123 patients (11.3\%) with PTC histology, when comparing with one of 50 patients (2\%) with follicular or Hürthle cell histology. In addition, thyroglobulin antibody ( $\mathrm{TgAb}$ ) was present in 12 of 123 patients (9.76\%) with PTC, while none of FTC patients presented TgAb at diagnosis, confirming the correlation between concurrent autoimmunity and PTC histology.

\section{Molecular Link between Thyroid Cancer and Chronic Lymphocytic Thyroiditis}

A functional relationship between chronic inflammation and cancer was first proposed by Virchow, in 1863, and has been sustained by clinical $[41,78]$ and epidemiological evidence [79-82]. Both a causal association and a noncausal association have been proposed, and the molecular mechanism that links inflammation and cancer is not completely clear so far. A link between thyroid cancer, in particular the PTC histotype, and AT has long been recognized, although the precise relationship between the two diseases remains subject of debate.

Hashimoto's thyroiditis is characterized by proliferating nodules as well as by cytological alterations and nuclear modifications similar to those of papillary carcinomas, suggesting that both neoplastic and autoimmune diseases could share the same molecular pathogenesis [83].

The mitogen-activated protein kinase (MAPK) signaling pathway is a foremost event in the carcinogenesis of the most common endocrine malignancy, the papillary thyroid carcinoma (PTC). Affected elements include RET/PTC rearrangements and point mutations of the RAS and BRAF genes. Mutations in these genes are found in over $70 \%$ of PTC, as previously reviewed [84]. Chromosomal RET rearrangements, called RET/PTC, result in constitutive ligandindependent activation of RET kinase, which was the first genetic anomaly detected in PTC and is found in 5-70\% of tumor samples. Although less frequently, the activation of other tyrosine kinase receptors, including NTRK1, c-Met, or EGFR, has also been reported in PTC [85]. The BRAF mutation represents the most common genetic alteration found in PTC [86]. More than $90 \%$ of BRAF mutations lead to a change of valine to glutamic acid at position 600 (V600E) [85]. Finally, RAS is the least affected molecule in the pathway [85]. All of these multisteps of thyroid carcinogenesis are shown in Figure 2.

Several authors have found RET/PTC rearrangements in non-neoplastic thyroid lesions, such as CLT [88-90]. In addition, Muzza et al. found RET/PTC1 being more represented in PTCs associated with autoimmunity than in PTC without autoimmunity, suggesting that the association between RET/PTC1 and thyroiditis points to a critical role of this oncoprotein in the modulation of the autoimmune response [41]. Rhoden et al. showed that low-level RET/PTC recombination occurs in nonneoplastic follicular cells of HT and in a subset of papillary thyroid carcinomas, indicating that overlapping molecular mechanisms may govern early stages of tumor development and inflammation in the thyroid [91]. Kang et al. studied the RET/PTC-RAS-BRAF in oxyphil cells in the vicinity of large lymphoid HT infiltrates and in malignant PTC cells. The expression of RET, nuclear RAS, and ERK proteins is greatly enhanced in PTC cells and HT oxyphil cells. Thus, the RET/PTC-RAS-BRAF cascade may be involved in the development of PTC and oxyphil 


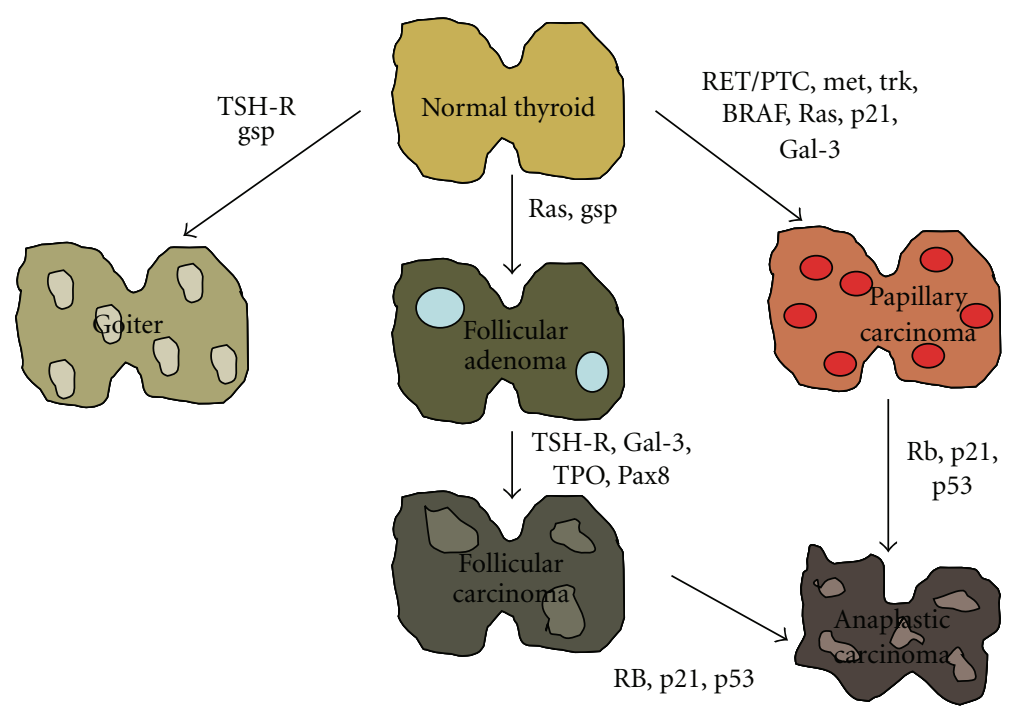

FIGURE 2: Multistep carcinogenesis model of thyroid cancer formation. Formation of benign thyroid tumors occurs as a result of alteration of various growth factors. Follicular neoplasms are formed from thyrocytes by mutations of RAS and other factors, as shown in the figure. Papillary cancers are formed by alterations in RET/PTC and other oncogenes. Undifferentiated tumors are formed from differentiated tumors by mutations of tumor suppressor genes (adapted from [87]).

cell metaplasia in HT. These results show the possibility of a molecular link between oxyphil cell metaplasia in HT and the progression of PTC [92].

However, different mechanisms could also explain the association between CLT and RET/PTC rearrangement (Figure 3). Chronic inflammation might facilitate the rearrangement or, conversely, RET/PTC rearrangement might promote chronic inflammation. The production of free radicals, cytokine secretion, cellular proliferation, and other phenomena correlated with inflammation might predispose to the rearrangement in follicular cells [93]. It is well known that leukocytes recruited under an inflammation context physiologically secrete reactive oxygen species and reactive nitrogen species. However, these highly reactive metabolites induce the production of peroxynitrite and other mutagenic agents, leading to "DNA damage", for example, mutations in proliferating cells [94]. Thus, in the case of persistent tissue damage, $\mathrm{O}_{2}$ and $\mathrm{N}$ highly reactive metabolites secreted by inflammatory cells induce point-mutations, DNA rearrangements, and double-strand breaks $[93,95]$.

Guarino et al. proposed that cytokines and chemokines released by inflammatory tumor stroma could sustain the survival of thyroid cells in which RET/PTC rearrangements randomly occur, thereby allowing the selection of clones that acquire additional genetic lesions and thus become resistant to oncogene-induced apoptosis [93]. In fact, some reports indicate that RET/PTC might induce apoptosis $[96,97]$. This hypothesis of interaction between RET/PTC rearrangement and thyroid inflammation is reinforced by some studies that suggest that thyroid cancer cells, like other epithelial cancer cells, can produce inflammatory factors that may facilitate cell survival, preventing apoptosis. Stassi et al. found that autocrine production of IL- 4 and IL-10 promotes thyroid tumor cell progression and resistance to chemotherapy by the upregulation of antiapoptotic proteins, such as Bcl-2 and Bcl-xL [98]. Conticello et al. found that IL-4 protects tumor cells (primary prostate, breast, and bladder cancer) from CD95- and chemotherapy-induced apoptosis by the upregulation of antiapoptotic proteins, such as cFLIP/FLAME-1 and Bcl-x(L) [99]. Todaro et al. identified that primary epithelial cancer cells from colon, breast, and lung carcinomas produced interleukin-4 (IL-4), which amplified the expression levels of these antiapoptotic proteins and prevented cell death induced upon exposure to drug agents via downregulation of the antiapoptotic factors PED, cFLIP, Bcl-xL, and Bcl-2, providing evidence that exogenous IL-4 was able to upregulate the expression levels of these antiapoptotic proteins and potently stabilized the growth of normal epithelial cells making them apoptosis resistant [100].

On the contrary, RET/PTC rearrangement might induce chronic inflammation. Russell et al. found that RET/PTC3 alone increases nuclear NF-kappaB activity and secretion of MCP-1 and GM-CSF. Finally, transfer of RP3-expressing thyrocytes into mice in vivo attracted dense macrophage infiltrates, leading to rapid thyroid cell death [101]. In addition, the same group found that IL1-alpha, IL1-beta, IL6, TNF-alpha, and the Cox2 enzyme are produced by RET/PTC3-transgenic thyroid tissue, but absent from nontransgenic thyroids, providing support for the notion that oncogene-induced cytokine secretion is important for the development and progression of thyroid carcinomas in genetically permissive hosts [102]. Prostaglandin E2, microsomal prostaglandin E2, cyclooxygenase 2 (Cox2), IL24, and other genes coding for proteins involved in the immune response and in intracellular signal transduction pathways activated by cytokines and chemokines have been suggested to be induced by RET/PTC, indicating that the expression 


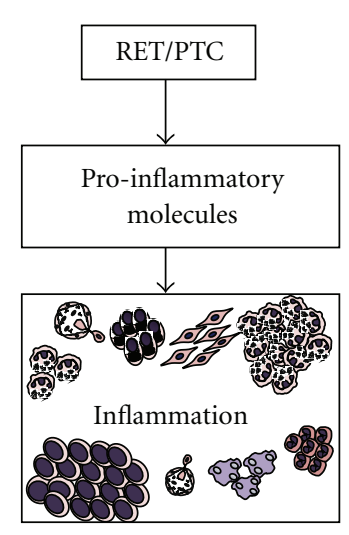

(a)

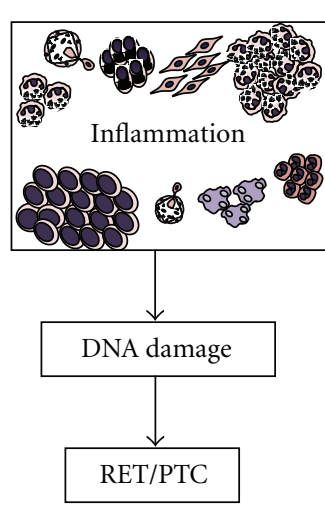

(b)

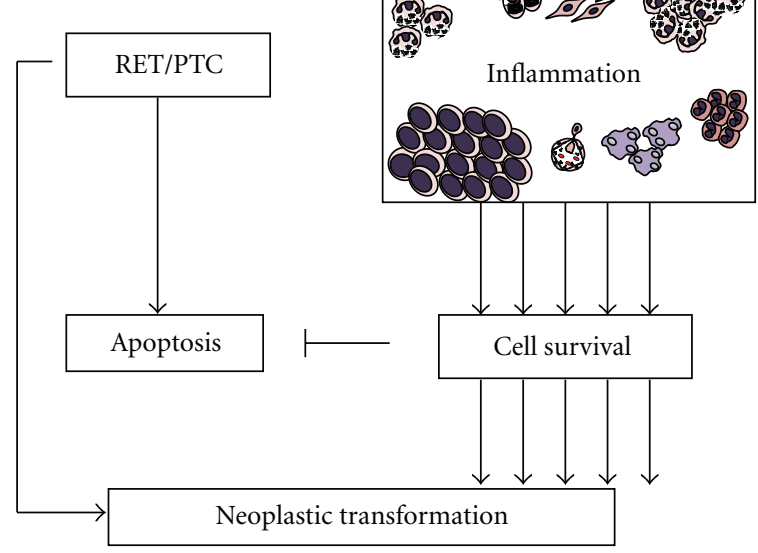

(c)

Figure 3: Putative links between RET/PTC rearrangement and concurrent thyroid inflammation. (a) RET/PTC could drive expression of several proinflammatory molecules that may elicit concurrent inflammation. Another possibility (b) is inflammation propitiating RET/PTC rearrangement. Inflammation produces reactive oxygen species and free radicals that may facilitate DNA damage and chromosomal abnormities, like RET/PTC rearrangement. (c) Molecules released by inflammation could sustain the survival of thyroid cells in which RET/PTC rearrangements randomly occur, thereby allowing the selection of clones that acquire additional genetic lesions and thus become resistant to oncogene-induced apoptosis.

of the oncogenic fusion protein RET/PTC is critical not only to thyroid cancer pathogenesis but also in the elicitation of inflammatory response [103-105].

$B R A F^{V 600 E}$ mutation is another common genetic alteration in PTC. Muzza et al. found BRAF ${ }^{V 600 E}$ being more represented in PTC without concurrent autoimmunity [41]. Furthermore, Kim et al. found that, in Korean patients with PTC, BRAFV600E mutation is associated with a lower frequency of background HT [39]. Studies on melanoma cells have given clues about mechanisms linking BRAF mutation and immune response. Molecules like interleukin (IL)-10, VEGF, IL-6, and IL-8 are thought to be induced by $B R A F^{V 600 E}$ mutation $[106,107]$.

The association between solid cell nest ( $\mathrm{SCN}$ ) of the thyroid and both neoplastic and autoimmune thyroid diseases is the most recent and debated issue. It is currently accepted that solid cell nests and the so-called mixed follicles are branchial body remnants [108-116], whose biological significance remains disputable $[108,109,117-$ 119]. Previous studies have described the histological and immunohistochemical features of SCN $[108,109,114,117$, 120-124]. Cameselle-Teijeiro et al. suggested that main cells of solid cell nests (SCNs) might be multipotential cells that could contribute to histogenesis of $\mathrm{C}$ cells and follicular cells, as well as to some thyroid tumors [119]. Recently, Preto et al. and Reis-Filho et al. reported that such main cells harbor the minimal properties of a stem cell phenotype (capacity for both self-renewal, conferred by telomerase activity, and differentiation to one or more types of specialized cells, given by the high expression of p63 and bcl-2) and may thus represent a pool of stem cells of the adult thyroid $[123,125]$. Burstein et al. hypothesized that SCN p63-positive cells are pluripotent and may stay undifferentiated or undergo benign squamoid or glandular maturation, thyroid follicular epithelial differentiation, and oncogenic change leading to papillary carcinoma or may trigger an immune reaction, resulting in lymphoid infiltration and Hashimoto's thyroiditis. Hence, Hashimoto's thyroiditis and papillary carcinoma would be etiologically linked because both disorders might be initiated by the same population of pluripotent p63-positive embryonal stem cell remnants [122]. SCN could represent incompletely developed thyroid tissue predisposed to autoimmune thyroid diseases, such as Hashimoto's thyroiditis, since the epithelia from the third and the fourth pouches have the ability to attract lymphocytes $[126,127]$. Cameselle-Teijeiro et al. described an unusual case of SCN hyperplasia coexisting with two papillary microcarcinomas, a follicular adenoma, hyperplastic nodules, and a few lymphoid aggregates [128]. A morphologic continuity between SCN and one papillary thyroid microcarcinoma was reported and the authors found the same BRAF ${ }^{V 600 E}$ mutation in both the SCN and the contiguous papillary thyroid microcarcinoma, suggesting a histogenetic link between the main cells of SCN and PTC, raising the possibility that SCN hyperplasia could be a precursor lesion of PTC [128]. These findings suggest that SCN may be a key point in the pathogenesis of both CLT and PTC.

Pathways of immune activation could exert a role in thyroid cancer and CLT link. Toll-like receptor (TLR) comprises a family of cell surface receptors involved in the recognition of pathogen-associated signature molecules that signal the activation of innate and adaptive immunity [129133]. Although the TLR family consists of more than ten members [133], in humans, TLR3 had been reported to be restricted primarily to dendritic cells of the immune system 
[134]. Harii et al. showed that TLR3 can be functionally overexpressed in cultured human thyrocytes by stimuli. Immunohistochemical showed that TLR3 protein is overexpressed in human thyrocytes surrounded by immune cells in $100 \%$ of patients diagnosed with Hashimoto's thyroiditis, but not in normal or Graves' thyrocytes, suggesting that TLR3 overexpression can induce an innate immune response in thyrocytes, which may be important in the pathogenesis of Hashimoto's thyroiditis and in immune cell infiltrates [129]. McCall et al. showed that PTC cells basally express TLR3 RNA and that TLR3 signal systems are functional in these cells. High basal TLR3 levels and TLR3 signals capable of increasing cytokines and chemokines in PTC cells in vitro are consistent with the existence of immune cell infiltrates in vivo, based on related studies suggesting that elevated TLR3/TLR3 signals in HT are associated with immune cell infiltrates $[129,135]$.

Studies on DNA damage and repair have recently yielded several intriguing connections between tumor biology and immune response. There is some evidence that ATM may exert a special role in the activation of the immune response. ATM is an essential component of cell cycle restriction point control. Its scope of interaction includes phosphorylation and activation of E2F1, p53, and Cdc25 family members, which inhibit cell cycle progression and activate DNA repair systems $[136,137]$. Gomez et al. showed that ATM protein expression was significantly downregulated in immunoresistant human glioma cell clones [138], indicating a possible immunogenic role of ATM gene. DNA damage signaling can directly engage the immune system in a non-cell-type-specific manner. ATM activation by genotoxic agents or stalled DNA replication induces ligands of the NKG2D receptor. These are expressed by natural killer cells and activated CD8+ T cells of the innate immune system [139]. In addition, authors indicated that polymorphisms of DNA damage response genes, such as ATM, XRCC1, TP53, XRCC3, and MTF1, may be potential risk modifiers of ionizing radiation-induced or sporadic PTCs $[140,141]$. Royer et al. reported that hOGG1, encoding human 8oxoguanine DNA glycosylase (hOGG1), a key enzyme for repairing DNA damaged by reactive oxygen species and loss of heterozygosity, is strongly associated with PTC and HT but not with benign thyroid, suggesting that thyroid follicular epithelia accumulate aberrant genetic changes in long-standing HT, which may represent a precursor lesion of PTC [142]. In fact, data from our group showed a significant correlation between ATM expression and concurrent CLT in DTC (not published data).

\section{Prognostic Implication of the Association between CLT and PTC}

It remains a matter of debate whether the association with a CLT or even an autoimmune disorder could affect the prognosis of PTC. In fact, a worse prognosis was reported in a few series $[72,143]$, whereas most of the studies showed either a protective effect of thyroid autoimmunity [34, 37, 40, 144] or a similar behavior between cancer with and without associated thyroiditis $[41,74]$, as shown in Table 1.
Our group reported a worse outcome in DTC patients with no evidence of autoimmune activity when compared with patients who reported an autoimmune thyroid disease and/or presented positive circulating thyroid autoantibodies, suggesting that autoimmune activity against the gland may exert a protective effect on the outcome of differentiated thyroid carcinoma patients [38].

However, it is unclear whether coexistent CLT represents a host immune response to DTC $[33,60,145]$ or just a chance occurrence $[40,146,147]$. The favorable clinical outcome in PTC patients with concurrent autoimmunity strongly suggests that a thyroid autoimmune response may enhance or even provide an antitumor attack. CLT is an autoimmune reaction to thyroid specific antigen, and this immune response may lead to destruction of thyroid tissue. Kim et al. [40] postulated that, as PTC cells originating from follicular cells expressed specific antigen of normal follicular cells, although in a less degree, coexistent CLT might be involved in destruction of tumor cells in much the same way as in advanced CLT. This immune reaction against tumor might be associated with a better prognosis for PTC patients with CLT. Studying the glands of autopsies performed in individuals from two different Brazilian regions (Rio Grande do Norte versus São Paulo), we found a high incidence of nonencapsulated nonsclerosing papillary thyroid microcarcinomas (PTM) in Rio Grande do Norte, an area of markedly high incidence of PTC, in sharp contrast with the prevalence of small sclerosing lesions in São Paulo, where clinical thyroid cancers are much more infrequent [148]. PTMs could elicit an inflammatory lymphocytic response, fibrosis, and the formation of a capsule impeding its further growth [148]. We could speculate that these lesions may never evolve to clinical cancers, in contrast with the nonencapsulated nonsclerosing lesions that could represent early stages of clinical PTC.

Conversely, antithyroid antibodies may be able to recognize these malignant cells and destroy them in the same way as they destroy normal follicular cells, contributing to the low rate of clinical progression of these lesions [32, 62, 149].

Muzza et al. [41] found no significant differences regarding either clinical and pathological features or outcomes between two matched groups of PTC patients with and without associated autoimmunity. The cases of PTC associated with lymphocytic thyroiditis (LT) are much more often multicentric than the nonassociated form of PTC [35]. Interestingly, those with multifocal tumors had a relatively high incidence of lymphocytic thyroiditis (62\%) in the remaining thyroid parenchyma during the definitive histological examination [150, 151]. Kim et al. [42] found that in metastatic papillary thyroid microcarcinomas, multifocality and bilaterality were more frequent in PTC with LT than without LT. Kim et al. [39] found that a background of Hashimoto's thyroiditis is more frequent in young patients, who trend to be patients with good prognosis. However, they found that the $B R A F^{V 600 E}$ mutation in PTC is associated with a low frequency of background Hashimoto's thyroiditis and high frequency of lymph-node metastasis, suggesting a paradoxical role of concurrent autoimmunity of PTC outcome. 
Some investigators have reported that the presence of CLT in PTC is associated with better prognosis, low recurrence rate, and less aggressive disease at presentation [33, 34, 36, 37, 40, 152, 153]. Despite some controversies, there is an emerging literature on the protective effect of CLT in patients with PTC. In a large retrospective study, Kashima et al. reported a 5\% cancer-specific mortality and a $85 \%$ relapse-free 10 -year survival rate in patients without CLT compared with $0-7 \%$ mortality and 95\% relapsefree 10-year survival rate with CLT [34]; this finding was very similar to Loh's results [37]. It is, however, not clear whether treatment modality, including extent of surgery, was comparable between those with and without CLT. Kebebew et al. reported that the presence of CLT was associated with an improved prognosis by univariate analysis, but it was not an independent factor [28], and this result was due to the fact that most patients with CLT had other good prognostic factors, such as young age and female gender. Kim et al. found a greater female preponderance in the patients with CLT when comparing with those without CLT. Mean tumor size in the patients with CLT was smaller than that in patients without CLT. One hundred and fiftyone $(12.3 \%)$ patients without CLT had recurrence, whereas $14(7.1 \%)$ patients with CLT had recurrence during the follow-up period [40]. Singh et al. [30] reported that the prognostic variables at the time of a diagnosis of papillary cancer and the approach to management are not altered by the presence of coexistent Hashimoto's thyroiditis. In addition, the rate of surgical complications was not higher in patients with coexistent Hashimoto's disease, suggesting that the presence of coexistent Hashimoto's thyroiditis does not affect the diagnostic evaluation or management of papillary thyroid cancers. However, meta-analysis suggested a positive correlation between Hashimoto's disease and disease-free survival and overall survival [30].

\section{Future Perspectives and Conclusion}

Cooccurrences of CLT and thyroid gland cancer have been repeatedly reported [21-28]. A better understanding about clinical implications of concurrent autoimmunity to thyroid cancer could lead to new insights of thyroid cancer immunotherapy. In addition, elucidation of the molecular mechanisms involved in autoimmune disease and concurrent cancer could help identify new therapeutic strategies against thyroid cancer. In fact, within the last decade, a multitude of different studies and clinical trials have been performed using immune cell therapies for different cancers. Cancer immunotherapy using dendritic cells (DC) or adoptive cytotoxic T-lymphocytes (CTLs) is very promising because malignant cells can be affected by the immune system without damaging healthy tissue and without dangerous side effects. In any case, the identification of tumor cell-specific antigens is crucial for establishing clinically effective tumor immunotherapy and monitoring the induced immune response. Up to now, however, no single tumor-associated antigen has been proven useful for primary follicular thyroid carcinomas, although a couple of candidates might have this potential [154]. Only antibody-based therapies were performed on nonmedullary thyroid cancer, and there is a broad spectrum to be explored on cellular therapy against DTC, mainly for those cases with aggressive manifestation [155-157].

Medullary thyroid cancer (MTC) can give us an example for immunotherapy against thyroid cancer. The polypeptide hormone calcitonin has been proposed as tumor antigen for immunotherapy in MTC. Since then, several vaccination trials have been performed in murine models and also in men. In humans, several studies used full-length calcitonin for priming DCs $[158,159]$. Thereafter, a new protocol with interferon- $\alpha$ generated DCs with direct tumor lysis activity was performed [160]. After a long-term follow-up of more than 48 months, two of five MTC patients showed stable disease with changes in tumor size and tumor marker of less than 25\% [161]. More studies are warranted to apply all these concepts to poorly differentiated and anaplastic thyroid cancer.

\section{Conflict of Interest}

There is no financial interest in or arrangement with a company whose product was used in a study. In addition, there is no financial interest in or arrangement with a competing company, and there are no other direct or indirect financial connections or other situations that might raise the question of bias in the work reported or the conclusions, implications, or opinions stated-including pertinent commercial or other sources of funding for the individual author(s) or for the associated department(s) or organization(s), personal relationships, or direct academic competition.

\section{References}

[1] American Cancer Society, Cancer Facts \& Figures, The Society, Atlanta, Ga, USA.

[2] L. Davies and H. G. Welch, "Increasing incidence of thyroid cancer in the United States, 1973-2002," Journal of the American Medical Association, vol. 295, no. 18, pp. 21642167, 2006.

[3] J. R. Burgess and P. Tucker, "Incidence trends for papillary thyroid carcinoma and their correlation with thyroid surgery and thyroid fine-needle aspirate cytology," Thyroid, vol. 16, no. 1, pp. 47-53, 2006.

[4] B. A. Kilfoy, T. Zheng, T. R. Holford et al., "International patterns and trends in thyroid cancer incidence, 1973-2002," Cancer Causes and Control, vol. 20, no. 5, pp. 525-531, 2009.

[5] Y. E. Nikiforov, "Is ionizing radiation responsible for the increasing incidence of thyroid cancer?" Cancer, vol. 116, no. 7, pp. 1626-1628, 2010.

[6] L. Wartofsky, "Increasing world incidence of thyroid cancer: increased detection or higher radiation exposure?" Hormones, vol. 9, no. 2, pp. 103-108, 2010.

[7] G. Pellegriti, F. De Vathaire, C. Scollo et al., "Papillary thyroid cancer incidence in the volcanic area of sicily," Journal of the National Cancer Institute, vol. 101, no. 22, pp. 1575-1583, 2009.

[8] E. D. Williams, A. Abrosimov, T. Bogdanova et al., "Morphologic characteristics of Chernobyl-related childhood 
papillary thyroid carcinomas are independent of radiation exposure but vary with iodine intake," Thyroid, vol. 18, no. 8, pp. 847-852, 2008.

[9] X. H. Liu, G. G. Chen, A. C. Vlantis, and C. A. Van Hasselt, "Iodine mediated mechanisms and thyroid carcinoma," Critical Reviews in Clinical Laboratory Sciences, vol. 46, no. 5-6, pp. 302-318, 2009.

[10] A. Y. Chen, A. Jemal, and E. M. Ward, "Increasing incidence of differentiated thyroid cancer in the United States, 19882005," Cancer, vol. 115, no. 16, pp. 3801-3807, 2009.

[11] A. G. Renehan, I. Soerjomataram, M. Tyson et al., "Incident cancer burden attributable to excess body mass index in 30 European countries," International Journal of Cancer, vol. 126, no. 3, pp. 692-702, 2010.

[12] E. C. Morari, J. L. Pereira Leite, F. Granja, L. V. Montalli da Assumpcão, and L. S. Ward, "The null genotype of glutathione S-transferase M1 and T1 locus increases the risk for thyroid cancer," Cancer Epidemiology Biomarkers and Prevention, vol. 11, no. 11, pp. 1485-1488, 2002.

[13] F. Granja, J. Morari, E. C. Morari, L. A. C. Correa, L. V. M. Assumpção, and L. S. Ward, "GST profiling may be useful in the screening for thyroid nodule malignancy," Cancer Letters, vol. 209, no. 2, pp. 129-137, 2004.

[14] F. Granja, J. Morari, E. C. Morari, L. A. C. Correa, L. V. M. Assumpção, and L. S. Ward, "Proline homozygosity in codon 72 of p53 is a factor of susceptibility for thyroid cancer," Cancer Letters, vol. 210, no. 2, pp. 151-157, 2004.

[15] F. Granja, E. C. Morari, L. V. M. Assumpção, and L. S. Ward, "GSTO polymorphism analysis in thyroid nodules suggest that GSTO1 variants do not influence the risk for malignancy," European Journal of Cancer Prevention, vol. 14, no. 3, pp. 277-280, 2005.

[16] N. E. Bufalo, J. L. Leite, A. C. T. Guilhen et al., "Smoking and susceptibility to thyroid cancer: an inverse association with CYP1A1 allelic variants," Endocrine-Related Cancer, vol. 13, no. 4, pp. 1185-1193, 2006.

[17] A. C. T. Guilhen, N. E. Bufalo, E. C. Morari et al., "Role of the N-Acetyltransferase 2 Detoxification system in thyroid cancer susceptibility," Clinical Cancer Research, vol. 15, no. 1, pp. 406-412, 2009.

[18] E. Ostroumova, A. Brenner, V. Oliynyk et al., "Subclinical hypothyroidism after radioiodine exposure: UkrainianAmerican cohort study of thyroid cancer and other thyroid diseases after the chornobyl accident (1998\&2000)," Environmental Health Perspectives, vol. 117, no. 5, pp. 745-750, 2009.

[19] I. Gomez Segovia, H. J. Gallowitsch, E. Kresnik et al., "Descriptive epidemiology of thyroid carcinoma in Carinthia, Austria: 1984-2001. Histopathologic features and tumor classification of 734 cases under elevated general iodination of table salt since 1990: population-based agestratified analysis on thyroid carcinoma incidence," Thyroid, vol. 14, no. 4, pp. 277-286, 2004.

[20] P. Laurberg, C. Cerqueira, L. Ovesen et al., "Iodine intake as a determinant of thyroid disorders in populations," Best Practice and Research, vol. 24, no. 1, pp. 13-27, 2010.

[21] M. E. Dailey, S. Lindsay, and R. Skahen, "Relation of thyroid neoplasms to Hashimoto disease of the thyroid gland," Archives of Surgery, vol. 70, no. 2, pp. 291-297, 1955.

[22] G. Crile Jr. and E. R. Fisher, "Simultaneous occurrence of thyroiditis and papillary carcinoma; report of two cases," Cancer, vol. 6, no. 1, pp. 57-62, 1953.

[23] R. N. Hirabayashi and S. Lindsay, "The relation of thyroid carcinoma and chronic thyroiditis," Surgery, Gynecology \& Obstetrics, vol. 121, pp. 243-252, 1965.
[24] C. P. Schlicke, J. E. Hill, and G. F. Schultz, "Carcinoma in chronic thyroiditis," Surgery, Gynecology \& Obstetrics, vol. 111, pp. 552-556, 1960.

[25] O. H. Clark, F. S. Greenspan, and J. E. Dunphy, "Hashimoto's thyroiditis and thyroid cancer: indications for operation," American Journal of Surgery, vol. 140, no. 1, pp. 65-71, 1980.

[26] S. Lindsay, M. E. Dailey, J. Friedlander, G. Yee, and M. H. Soley, "Chronic thyroiditis: a clinical and pathologic study of 354 patients," The Journal of Clinical Endocrinology and Metabolism, vol. 12, no. 12, pp. 1578-1600, 1952.

[27] D. W. Meier, O. H. Woolner, P. H. G. Beahrs, and C. W. Mc, "Parenchymal findings in thyroidal carcinoma: pathologic study of 256 cases," Journal of Clinical Endocrinology \& Metabolism, vol. 19, no. 1, pp. 162-171, 1959.

[28] E. Kebebew, P. A. Treseler, P. H. G. Ituarte, and O. H. Clark, "Coexisting chronic lymphocytic thyroiditis and papillary thyroid cancer revisited," World Journal of Surgery, vol. 25, no. 5, pp. 632-637, 2001.

[29] J. M. B. Bloodworth, J. Lechago, and V. E. Gould, Bloodworth's Endocrine Pathology, Williams \& Wilkins, Baltimore, Md, USA, 3rd edition, 1996.

[30] B. Singh, A. R. Shaha, H. Trivedi, J. F. Carew, A. Poluri, and J. P. Shah, "Coexistent Hashimoto's thyroiditis with papillary thyroid carcinoma: impact on presentation, management, and outcome," Surgery, vol. 126, no. 6, pp. 1070-1077, 1999.

[31] L. S. Ward and L. V. M. Assumpção, "The impact of gender in differentiated thyroid cancer," Clinical Endocrinology, vol. 66, no. 5, pp. 752-753, 2007.

[32] P. S. De Matos, A. P. C. Ferreira, and L. S. Ward, "Prevalence of papillary microcarcinoma of the thyroid in Brazilian autopsy and surgical series," Endocrine Pathology, vol. 17, no. 2, pp. 165-173, 2006.

[33] S. Matsubayashi, K. Kawai, Y. Matsumoto et al., "The correlation between papillary thyroid carcinoma and lymphocytic infiltration in the thyroid gland," Journal of Clinical Endocrinology and Metabolism, vol. 80, no. 12, pp. 34193424, 1995.

[34] K. Kashima, S. Yokoyama, S. Noguchi et al., "Chronic thyroiditis as a favorable prognostic factor in papillary thyroid carcinoma," Thyroid, vol. 8, no. 3, pp. 197-202, 1998.

[35] K. Asanuma, A. Sugenoya, Y. Kasuga, N. Itoh, S. Kobayashi, and J. Amano, "The relationship between multiple intrathyroidal involvement in papillary thyroid carcinoma and chronic non-specific thyroiditis," Cancer Letters, vol. 122, no. 1-2, pp. 177-180, 1998.

[36] A. Schäffler, K. D. Palitzsch, C. Seiffarth et al., "Coexistent thyroiditis is associated with lower tumour stage in thyroid carcinoma," European Journal of Clinical Investigation, vol. 28, no. 10, pp. 838-844, 1998.

[37] K. C. Loh, F. S. Greenspan, F. Dong, T. R. Miller, and P. P. B. Yeo, "Influence of lymphocytic thyroiditis on the prognostic outcome of patients with papillary thyroid carcinoma," Journal of Clinical Endocrinology and Metabolism, vol. 84, no. 2, pp. 458-463, 1999.

[38] S. Lisboa Souza, L. Vera Montalli da Assumpção, and L. Sterian Ward, "Impact of previous thyroid autoimmune diseases on prognosis of patients with well-differentiated thyroid cancer," Thyroid, vol. 13, no. 5, pp. 491-495, 2003.

[39] S. K. Kim, K. H. Song, SO. D. Lim et al., "Clinical and pathological features and the BRAF mutation in patients with papillary thyroid carcinoma with and without concurrent Hashimoto thyroiditis," Thyroid, vol. 19, no. 2, pp. 137-141, 2009. 
[40] E. Y. Kim, W. G. Kim, W. B. Kim et al., "Coexistence of chronic lymphocytic thyroiditis is associated with lower recurrence rates in patients with papillary thyroid carcinoma," Clinical Endocrinology, vol. 71, no. 4, pp. 581-586, 2009.

[41] M. Muzza, D. Degl'Innocenti, C. Colombo et al., "The tight relationship between papillary thyroid cancer, autoimmunity and inflammation: clinical and molecular studies," Clinical Endocrinology, vol. 72, no. 5, pp. 702-708, 2010.

[42] H. S. Kim, Y. J. Choi, and JI. S. Yun, "Features of papillary thyroid microcarcinoma in the presence and absence of lymphocytic thyroiditis," Endocrine Pathology, pp. 1-5, 2010.

[43] B. Rapoport and S. M. McLachlan, "Thyroid autoimmunity," Journal of Clinical Investigation, vol. 108, no. 9, pp. 12531259, 2001.

[44] L. A. Zenewicz, C. Abraham, R. A. Flavell, and J. H. Cho, "Unraveling the genetics of autoimmunity," Cell, vol. 140, no. 6, pp. 791-797, 2010.

[45] A. W. Michels and G. S. Eisenbarth, "Immunologic endocrine disorders," Journal of Allergy and Clinical Immunology, vol. 125, no. 2, pp. S226-S237, 2010.

[46] C. L. Burek and N. R. Rose, "Autoimmune thyroiditis and ROS," Autoimmunity Reviews, vol. 7, no. 7, pp. 530-537, 2008.

[47] Y. Tomer and F. Menconi, "Interferon induced thyroiditis," Best Practice and Research, vol. 23, no. 6, pp. 703-712, 2009.

[48] J. C. Flynn, D. J. McCormick, V. Brusic et al., "Pathogenic human thyroglobulin peptides in HLA-DR3 transgenic mouse model of autoimmune thyroiditis," Cellular Immunology, vol. 229, no. 2, pp. 79-85, 2004.

[49] F. Pacifico and A. Leonardi, "Role of NF- $\kappa$ B in thyroid cancer," Molecular and Cellular Endocrinology, vol. 321, no. 1, pp. 29-35, 2010.

[50] C. Anil, S. Goksel, and A. Gursoy, "Thyroglobulin antibody is associated with increased cancer risk in thyroid nodules," Thyroid, vol. 20, no. 8, pp. 885-891, 2010.

[51] Drug Discovery Today, Elsevier Science, Oxford, UK, 10th edition, 2004.

[52] S. Shu, G. E. Plautz, J. C. Krauss, and A. E. Chang, "Tumor immunology," Journal of the American Medical Association, vol. 278, no. 22, pp. 1972-1981, 1997.

[53] E. H. Lipford III, J. C. Eggleston, and K. D. Lillemoe, "Prognostic factors in surgically resected limited-stage, nonsmall cell carcinoma of the lung," American Journal of Surgical Pathology, vol. 8, no. 5, pp. 357-365, 1984.

[54] A. Kawata, Y. Une, M. Hosokawa, J. Uchino, and H. Kobayashi, "Tumor-infiltrating lymphocytes and prognosis of hepatocellular carcinoma," Japanese Journal of Clinical Oncology, vol. 22, no. 4, pp. 256-263, 1992.

[55] P. C. Kolbeck, F. F. Kaveggia, S. L. Johansson, M. T. Grune, and R. J. Taylor, "The relationships among tumorinfiltrating lymphocytes, histopathologic findings, and longterm clinical follow-up in renal cell carcinoma," Modern Pathology, vol. 5, no. 4, pp. 420-425, 1992.

[56] C. M. Boyd and J. R. Baker, "The immunology of thyroid cancer," Endocrinology and Metabolism Clinics of North America, vol. 25, no. 1, pp. 159-179, 1996.

[57] D. M. Tamimi, "The association between chronic lymphocytic thyroiditis and thyroid tumors," International Journal of Surgical Pathology, vol. 10, no. 2, pp. 141-146, 2002.

[58] K. Gul, A. Dirikoc, G. Kiyak et al., "The association between thyroid carcinoma and Hashimoto's thyroiditis: the ultrasonographic and histopathologic characteristics of malignant nodules," Thyroid, vol. 20, no. 8, pp. 873-878, 2010.
[59] J. H. Shull, N. Sharon, T. A. Victor, and E. F. Scanlon, "Thyroid carcinoma. Immunology, irradiation, and lymphocytic infiltration," Archives of Surgery, vol. 114, no. 6, pp. 729-731, 1979.

[60] H. Kamma, K. Fujii, and T. Ogata, "Lymphocytic infiltration in juvenile thyroid carcinoma," Cancer, vol. 62, no. 9, pp. 1988-1993, 1988.

[61] R. S. Sundick, "Iodine in autoimmune thyroiditis," Immunology series, vol. 52, pp. 213-228, 1990.

[62] F. Boi, M. L. Lai, B. Marziani, L. Minerba, G. Faa, and S. Mariotti, "High prevalence of suspicious cytology in thyroid nodules associated with positive thyroid autoantibodies," European Journal of Endocrinology, vol. 153, no. 5, pp. 637642, 2005.

[63] E. Fiore, T. Rago, M. Scutari et al., "Papillary thyroid cancer, although strongly associated with lymphocitic infiltration on histology, is only weakly predicted by serum thyroid autoantibodies in patients with nodular thyroid diseases," Journal of Endocrinological Investigation, vol. 32, no. 4, pp. 344-351, 2009.

[64] K. Boelaert, J. Horacek, R. L. Holder, J. C. Watkinson, M. C. Sheppard, and J. A. Franklyn, "Serum thyrotropin concentration as a novel predictor of malignancy in thyroid nodules investigated by fine-needle aspiration," Journal of Clinical Endocrinology and Metabolism, vol. 91, no. 11, pp. 4295-4301, 2006.

[65] T. Rago, G. Di Coscio, C. Ugolini et al., "Clinical features of thyroid autoimmunity are associated with thyroiditis on histology and are not predictive of malignancy in 570 patients with indeterminate nodules on cytology who had a thyroidectomy," Clinical Endocrinology, vol. 67, no. 3, pp. 363-369, 2007.

[66] E. Fiore, T. Rago, M. A. Provenzale et al., "Lower levels of TSH are associated with a lower risk of papillary thyroid cancer in patients with thyroid nodular disease: thyroid autonomy may play a protective role," Endocrine-Related Cancer, vol. 16, no. 4, pp. 1251-1260, 2009.

[67] M. Erdogan, N. Erdem, S. Cetinkalp et al., "Demographic, clinical, laboratory, ultrasonographic, and cytological features of patients with Hashimoto's thyroiditis: results of a university hospital of 769 patients in Turkey," Endocrine, vol. 36, no. 3, pp. 486-490, 2009.

[68] H. J. Carson, M. J. Castelli, and P. Gattuso, "Incidence of neoplasia in Hashimoto's thyroiditis: a fine-needle aspiration study," Diagnostic Cytopathology, vol. 14, no. 1, pp. 38-42, 1996.

[69] E. L. Mazzaferri, “Thyroid cancer and Graves' disease," Journal of Clinical Endocrinology and Metabolism, vol. 70, no. 4, pp. 826-829, 1990.

[70] E. L. Mazzaferri, “Thyroid cancer and Graves' disease: the controversy ten years later," Endocrine Practice, vol. 6, no. 2, pp. 221-225, 2000.

[71] A. Belfiore, M. R. Garofalo, D. Giuffrida et al., "Increased aggressiveness of thyroid cancer in patients with Graves' disease," Journal of Clinical Endocrinology and Metabolism, vol. 70, no. 4, pp. 830-835, 1990.

[72] G. Pellegriti, A. Belfiore, D. Giuffrida, L. Lupo, and R. Vigneri, "Outcome of differentiated thyroid cancer in Graves' patients," Journal of Clinical Endocrinology and Metabolism, vol. 83, no. 8, pp. 2805-2809, 1998.

[73] A. Belfiore, D. Russo, R. Vigneri, and S. Filetti, "Graves' disease, thyroid nodules and thyroid cancer," Clinical Endocrinology, vol. 55, no. 6, pp. 711-718, 2001. 
[74] Y. Yano, H. Shibuya, W. Kitagawa et al., "Recent outcome of grave's disease patients with papillary thyroid cancer," European Journal of Endocrinology, vol. 157, no. 3, pp. 325329, 2007.

[75] I. B. Hales, A. McElduff, P. Crummer et al., 'Does Graves' disease or thyrotoxicosis affect the prognosis of thyroid cancer," Journal of Clinical Endocrinology and Metabolism, vol. 75, no. 3, pp. 886-889, 1992.

[76] L. J. DeGroot, E. L. Kaplan, M. McCormick, and F. H. Straus, "Natural history, treatment, and course of papillary thyroid carcinoma," Journal of Clinical Endocrinology and Metabolism, vol. 71, no. 2, pp. 414-424, 1990.

[77] O. H. Clark, "Predictors of thyroid tumor aggressiveness," Western Journal of Medicine, vol. 165, no. 3, pp. 131-138, 1996.

[78] F. Balkwill and A. Mantovani, "Inflammation and cancer: back to virchow?" Lancet, vol. 357, no. 9255, pp. 539-545, 2001.

[79] P. Correa, "Human gastric carcinogenesis: a multistep and multifactorial process-first American Cancer Society Award lecture on cancer epidemiology and prevention," Cancer Research, vol. 52, no. 24, pp. 6735-6740, 1992.

[80] A. Ekbom, C. Helmick, M. Zack, and H. O. Adami, "Ulcerative colitis and colorectal cancer: a population-based study," New England Journal of Medicine, vol. 323, no. 18, pp. 1228-1233, 1990.

[81] A. C. De Vries, J. Haringsma, and E. J. Kuipers, "The detection, surveillance and treatment of premalignant gastric lesions related to Helicobacter pylori infection," Helicobacter, vol. 12, no. 1, pp. 1-15, 2007.

[82] A. C. de Vries, N. C. T. van Grieken, C. W. N. Looman et al., "Gastric cancer risk in patients with premalignant gastric lesions: a nationwide cohort study in the Netherlands," Gastroenterology, vol. 134, no. 4, pp. 945-952, 2008.

[83] A. P. Weetman, "Cellular immune responses in autoimmune thyroid disease," Clinical Endocrinology, vol. 61, no. 4, pp. 405-413, 2004.

[84] R. Ciampi and Y. E. Nikiforov, "Minireview: RET/PTC rearrangements and braf mutations in thyroid tumorigenesis," Endocrinology, vol. 148, no. 3, pp. 936-941, 2007.

[85] C. Zafon and G. Obiols, "The mitogen-activated protein kinase (MAPK) signaling pathway in papillary thyroid cancer. From the molecular bases to clinical practiceVía de señalización dependiente de la proteincinasa de activación mitogénica en el carcinoma papilar de tiroides. De las bases moleculares a la práctica clínica," Endocrinologia y Nutricion, vol. 56, no. 4, pp. 176-186, 2009.

[86] M. Xing, "BRAF mutation in thyroid cancer," EndocrineRelated Cancer, vol. 12, no. 2, pp. 245-262, 2005.

[87] R.H. Williams and P.R. Larsen, Williams Textbook of Endocrinology, Saunders, Philadelphia, Pa, USA, 10th edition, 2003.

[88] A. Wirtschafter, R. Schmidt, D. Rosen et al., "Expression of the RET/PTC fusion gene as a marker for papillary carcinoma in Hashimoto's thyroiditis," Laryngoscope, vol. 107, no. 1, pp. 95-100, 1997.

[89] O. M. Sheils, J. J. O'Leary, V. Uhlmann, K. Lüttich, and E. C. Sweeney, "ret/PTC-1 activation in Hashimoto thyroiditis," International Journal of Surgical Pathology, vol. 8, no. 3, pp. 185-189, 2000.

[90] R. Elisei, C. Romei, T. Vorontsova et al., "RET/PTC rearrangements in thyroid nodules: studies in irradiated and not irradiated, malignant and benign thyroid lesions in children and adults," Journal of Clinical Endocrinology and Metabolism, vol. 86, no. 7, pp. 3211-3216, 2001.

[91] K. J. Rhoden, K. Unger, G. Salvatore et al., "RET/papillary thyroid cancer rearrangement in nonneoplastic thyrocytes: follicular cells of Hashimoto's thyroiditis share low-level recombination events with a subset of papillary carcinoma," Journal of Clinical Endocrinology and Metabolism, vol. 91, no. 6, pp. 2414-2423, 2006.

[92] D. Y. Kang, K. H. Kim, J. M. Kim et al., "High prevalence of RET, RAS, and ERK expression in Hashimoto's thyroiditis and in papillary thyroid carcinoma in the Korean population," Thyroid, vol. 17, no. 11, pp. 1031-1038, 2007.

[93] V. Guarino, M. D. Castellone, E. Avilla, and R. M. Melillo, "Thyroid cancer and inflammation," Molecular and Cellular Endocrinology, vol. 321, no. 1, pp. 94-102, 2010.

[94] L. M. Coussens and Z. Werb, "Inflammation and cancer," Nature, vol. 420, no. 6917, pp. 860-867, 2002.

[95] F. Colotta, P. Allavena, A. Sica, C. Garlanda, and A. Mantovani, "Cancer-related inflammation, the seventh hallmark of cancer: links to genetic instability," Carcinogenesis, vol. 30, no. 7, pp. 1073-1081, 2009.

[96] M. D. Castellone, A. M. Cirafici, G. De Vita et al., "Rasmediated apoptosis of PC CL 3 rat thyroid cells induced by RET/PTC oncogenes," Oncogene, vol. 22, no. 2, pp. 246-255, 2003.

[97] J. Wang, J. A. Knauf, S. Basu et al., "Conditional expression of RET/PTC induces a weak oncogenic drive in thyroid PCCL3 cells and inhibits thyrotropin action at multiple levels," Molecular Endocrinology, vol. 17, no. 7, pp. 1425-1436, 2003.

[98] G. Stassi, M. Todaro, M. Zerilli et al., "Thyroid cancer resistance to chemotherapeutic drugs via autocrine production of interleukin-4 and interleukin-10," Cancer Research, vol. 63, no. 20, pp. 6784-6790, 2003.

[99] C. Conticello, F. Pedini, A. Zeuner et al., "IL-4 protects tumor cells from anti-CD95 and chemotherapeutic agents via upregulation of antiapoptotic proteins," Journal of Immunology, vol. 172, no. 9, pp. 5467-5477, 2004.

[100] M. Todaro, Y. Lombardo, M. G. Francipane et al., "Apoptosis resistance in epithelial tumors is mediated by tumor-cellderived interleukin-4," Cell Death and Differentiation, vol. 15, no. 4, pp. 762-772, 2008.

[101] J. P. Russell, S. Shinohara, R. M. Melillo, M. D. Castellone, M. Santoro, and J. L. Rothstein, "Tyrosine kinase oncoprotein, RET/PTC3, induces the secretion of myeloid growth and chemotactic factors," Oncogene, vol. 22, no. 29, pp. 45694577, 2003.

[102] J. P. Russell, J. B. Engiles, and J. L. Rothstein, "Proinflammatory mediators and genetic background in oncogene mediated tumor progression," Journal of Immunology, vol. 172, no. 7, pp. 4059-4067, 2004.

[103] E. Puxeddu, N. Mitsutake, J. A. Knauf et al., "Microsomal prostaglandin E2 synthase-1 is induced by conditional expression of RET/PTC in thyroid PCCL3 cells through the activation of the MEK-ERK pathway," Journal of Biological Chemistry, vol. 278, no. 52, pp. 52131-52138, 2003.

[104] S. Shinohara and J. L. Rothstein, "Interleukin 24 is induced by the RET/PTC3 oncoprotein and is an autocrine growth factor for epithelial cells," Oncogene, vol. 23, no. 45, pp. 7571-7579, 2004.

[105] E. Puxeddu, J. A. Knauf, M. A. Sartor et al., "RET/PTCinduced gene expression in thyroid PCCL3 cells reveals early activation of genes involved in regulation of the immune response," Endocrine-Related Cancer, vol. 12, no. 2, pp. 319334, 2005. 
[106] H. Sumimoto, F. Imabayashi, T. Iwata, and Y. Kawakami, "The BRAF-MAPK signaling pathway is essential for cancerimmune evasion in human melanoma cells," Journal of Experimental Medicine, vol. 203, no. 7, pp. 1651-1656, 2006.

[107] S. Crawford, D. Belajic, J. Wei et al., "A novel B-RAF inhibitor blocks interleukin-8 (IL-8) synthesis in human melanoma xenografts, revealing IL-8 as a potential pharmacodynamic biomarker," Molecular Cancer Therapeutics, vol. 7, no. 3, pp. 492-499, 2008.

[108] H. R. Harach, "Solid cell nests of the thyroid," Journal of Pathology, vol. 155, no. 3, pp. 191-200, 1988.

[109] J. Cameselle-Teijeiro, J. Varela-Duran, C. Sambade, J. P. Villanueva, R. Varela- Nunez, and M. Sobrinho-Simoes, "Solid cell nests of the thyroid: light microscopy and immunohistochemical profile," Human Pathology, vol. 25, no. 7, pp. 684-693, 1994.

[110] V. Martin, L. Martin, G. Viennet, M. Hergel, J. P. Carbillet, and D. Fellmann, "Ultrastructural features of 'solid cell nest' of the human thyroid gland: a study of 8 cases," Ultrastructural Pathology, vol. 24, no. 1, pp. 1-8, 2000.

[111] H. Ruben Harach, "Mixed follicles of the human thyroid gland," Acta Anatomica, vol. 129, no. 1, pp. 27-30, 1987.

[112] V. L. Bykov, "Tissue of ultimobranchial origin in normal and pathologically altered thyroid gland," Arkhiv Patologii, vol. 55, no. 5, pp. 81-84, 1993.

[113] B. A. Fraser and J. W. A. Duckworth, "Ultimobranchial body cysts in the human foetal thyroid: pathological implications," Journal of Pathology, vol. 127, no. 2, pp. 89-92, 1979.

[114] Y. Mizukami, A. Nonomura, T. Michigishi et al., "Solid cell nests of the thyroid: a histologic and immunohistochemical study," American Journal of Clinical Pathology, vol. 101, no. 2, pp. 186-191, 1994.

[115] O. Ozaki, K. Ito, K. Sugino et al., "Solid cell nests of the thyroid gland," Virchows Archiv-A Pathological Anatomy and Histopathology, vol. 418, no. 3, pp. 201-205, 1991.

[116] M. E. Beckner, J. J. Shultz, and T. Richardson, "Solid and cystic ultimobranchial body remnants in the thyroid," Archives of Pathology and Laboratory Medicine, vol. 114, no. 10, pp. 1049-1052, 1990.

[117] V. Martin, L. Martin, G. Viennet, B. Challier, J. P. Carbillet, and D. Fellmann, "Solid cell nests and thyroid pathologies. Retrospective study of 1,390 thyroids," Annales de Pathologie, vol. 20, no. 3, pp. 196-201, 2000.

[118] J. K. C. Chan and C. C. H. Tse, "Solid cell nest-associated C-cells: another possible explanation for "C-cell hyperplasia" adjacent to follicular cell tumors," Human Pathology, vol. 20, no. 5, pp. 498-499, 1989.

[119] J. Cameselle-Teijeiro, C. Febles-Perez, and M. SobrinhoSimoes, "Papillary and mucoepidermoid carcinoma of the thyroid with anaplastic transformation. A case report with histologic and immunohistochemical findings that support a provocative histogenetic hypothesis," Pathology Research and Practice, vol. 191, no. 12, pp. 1214-1221, 1995.

[120] E. D. Williams, C. E. Toyn, and H. R. Harach, "The ultimobranchial gland and congenital thyroid abnormalities in man," Journal of Pathology, vol. 159, no. 2, pp. 135-141, 1989.

[121] P. Unger, M. Ewart, B. Y. Wang, LI. Gan, D. S. Kohtz, and D. E. Burstein, "Expression of p63 in papillary thyroid carcinoma and in Hashimoto's thyroiditis: a pathobiologic link?" Human Pathology, vol. 34, no. 8, pp. 764-769, 2003.

[122] D. E. Burstein, C. Nagi, B. Y. Wang, and P. Unger, "Immunohistochemical detection of p53 homolog p63 in solid cell nests, papillary thyroid carcinoma, and Hashimoto's thyroiditis: a stem cell Hypothesis of papillary carcinoma oncogenesis," Human Pathology, vol. 35, no. 4, pp. 465-473, 2004.

[123] A. Preto, J. Cameselle-Teijeiro, J. Moldes-Boullosa et al., "Telomerase expression and proliferative activity suggest a stem cell role for thyroid solid cell nests," Modern Pathology, vol. 17, no. 7, pp. 819-826, 2004.

[124] S. Asioli, L. A. Erickson, and R. V. Lloyd, "Solid cell nests in hashimoto's thyroiditis sharing features with papillary thyroid microcarcinoma," Endocrine Pathology, vol. 20, no. 4, pp. 197-203, 2009.

[125] J. S. Reis-Filho, A. Preto, P. Soares, S. Ricardo, J. CameselleTeijeiro, and M. Sobrinho-Simões, "p63 expression in solid cell nests of the thyroid: further evidence for a stem cell origin," Modern Pathology, vol. 16, no. 1, pp. 43-48, 2003.

[126] I. Vollenweider and C. Hedinger, "Solid cell nests (SCN) in Hashimoto's thyroiditis," Virchows Archiv-A Pathological Anatomy and Histopathology, vol. 412, no. 4, pp. 357-363, 1988.

[127] G. Prod'hom and C. Hedinger, "Relationship between solid cell nests and focal lymphocytic thyroiditis," Annales de Pathologie, vol. 5, no. 4-5, pp. 265-270, 1985.

[128] J. Cameselle-Teijeiro, I. Abdulkader, R. Pérez-Becerra et al., "BRAF mutation in solid cell nest hyperplasia associated with papillary thyroid carcinoma. A precursor lesion?" Human Pathology, vol. 40, no. 7, pp. 1029-1035, 2009.

[129] N. Harii, C. J. Lewis, V. Vasko et al., "Thyrocytes express a functional Toll-like receptor 3: overexpression can be induced by viral infection and reversed by phenylmethimazole and is associated with Hashimoto's autoimmune thyroiditis," Molecular Endocrinology, vol. 19, no. 5, pp. 12311250, 2005.

[130] K. Takeda and S. Akira, "Microbial recognition by Toll-like receptors," Journal of Dermatological Science, vol. 34, no. 2, pp. 73-82, 2004.

[131] D. M. Underhill, "Toll-like receptors: networking for success," European Journal of Immunology, vol. 33, no. 7, pp. 1767-1775, 2003.

[132] G. M. Barton and R. Medzhitov, "Toll-like receptor signaling pathways," Science, vol. 300, no. 5625, pp. 1524-1525, 2003.

[133] K. Takeda, T. Kaisho, and S. Akira, "Toll-like receptors," Annual Review of Immunology, vol. 21, pp. 335-376, 2003.

[134] M. Muzio, D. Bosisio, N. Polentarutti et al., "Differential expression and regulation of toll-like receptors (TLR) in human leukocytes: selective expression of TLR3 in dendritic cells," Journal of Immunology, vol. 164, no. 11, pp. 5998-6004, 2000.

[135] K. D. McCall, N. Harii, C. J. Lewis et al., "High basal levels of functional Toll-Like Receptor 3 (TLR3) and noncanonical Wnt5a are expressed in papillary thyroid cancer and are coordinately decreased by phenylmethimazole together with cell proliferation and migration," Endocrinology, vol. 148, no. 9, pp. 4226-4237, 2007.

[136] A. Sancar, L. A. Lindsey-Boltz, K. Ünsal-Kaçmaz, and S. Linn, "Molecular mechanisms of mammalian DNA repair and the DNA damage checkpoints," Annual Review of Biochemistry, vol. 73, pp. 39-85, 2004.

[137] S. Gasser and D. Raulet, "The DNA damage response, immunity and cancer," Seminars in Cancer Biology, vol. 16, no. 5, pp. 344-347, 2006.

[138] G. G. Gomez, M. J. Hickey, R. Tritz, and C. A. Kruse, "Immunoresistant human glioma cell clones selected with alloreactive cytotoxic $\mathrm{T}$ lymphocytes: downregulation of 
multiple proapoptotic factors," Gene Therapy and Molecular Biology, vol. 12, no. 1, pp. 101-110, 2008.

[139] S. Gasser, S. Orsulic, E. J. Brown, and D. H. Raulet, “The DNA damage pathway regulates innate immune system ligands of the NKG2D receptor," Nature, vol. 436, no. 7054, pp. 11861190, 2005.

[140] N. M. Akulevich, V. A. Saenko, T. I. Rogounovitch et al., "Polymorphisms of DNA damage response genes in radiation-related and sporadic papillary thyroid carcinoma," Endocrine-Related Cancer, vol. 16, no. 2, pp. 491-503, 2009.

[141] S. L. Dombernowsky, M. Weischer, K. H. Allin, S. E. Bojesen, A. Tybjærg-Hansen, and B. G. Nordestgaard, "Risk of cancer by ATM missense mutations in the general population," Journal of Clinical Oncology, vol. 26, no. 18, pp. 3057-3062, 2008.

[142] M. C. Royer, H. Zhang, C. Y. Fan, and M. S. Kokoska, "Genetic alterations in papillary thyroid carcinoma and hashimoto thyroiditis: an analysis of hOGG1 loss of heterozygosity," Archives of Otolaryngology, vol. 136, no. 3, pp. 240242, 2010.

[143] O. Ozaki, K. Ito, K. Kobayashi, K. Toshima, H. Iwasaki, and T. Yashiro, "Thyroid carcinoma in Graves' disease," World Journal of Surgery, vol. 14, no. 3, pp. 437-440, 1990.

[144] S. Gupta, A. Patel, A. Folstad et al., "Infiltration of differentiated thyroid carcinoma by proliferating lymphocytes is associated with improved disease-free survival for children and young adults," Journal of Clinical Endocrinology and Metabolism, vol. 86, no. 3, pp. 1346-1354, 2001.

[145] D. R. Maceri, M. J. Sullivan, and K. D. McClatchney, "Autoimmune thyroiditis: pathophysiology and relationship to thyroid cancer," Laryngoscope, vol. 96, no. 1, pp. 83-86, 1986.

[146] G. Crile, "Struma lymphomatosa and carcinoma of the thyroid," Surgery Gynecology and Obstetrics, vol. 147, no. 3, pp. 350-352, 1978.

[147] L. E. Holm, H. Blomgren, and T. Lowhagen, "Cancer risks in patients with chronic lymphocytic thyroiditis," New England Journal of Medicine, vol. 312, no. 10, pp. 601-604, 1985.

[148] A. M. D. O. Ramos, A. D. O. Sales, L. E. Barbalho De Mello et al., "Absence of peritumoral fibrosis or inflammatory infiltrate may be related to clinical progression of papillary thyroid microcarcinoma," International Journal of Surgical Pathology, vol. 17, no. 6, pp. 432-437, 2009.

[149] S. D. Lucas, A. Karlsson-Parra, BO. Nilsson et al., "Tumorspecific deposition of immunoglobulin $g$ and complement in papillary thyroid carcinoma," Human Pathology, vol. 27, no. 12, pp. 1329-1335, 1996.

[150] G. H. Sakorafas, J. Giotakis, and V. Stafyla, "Papillary thyroid microcarcinoma: a surgical perspective," Cancer Treatment Reviews, vol. 31, no. 6, pp. 423-438, 2005.

[151] L. Falvo, C. D’Ercole, S. Sorrenti et al., "Papillary microcarcinoma of the thyroid gland: analysis of prognostic factors including histological subtype," European Journal of Surgery, Supplement, vol. 168, no. 588, pp. 28-32, 2003.

[152] O. Ozaki, K. Ito, T. Mimura, K. Sugino, and Y. Hosoda, "Papillary carcinoma of the thyroid: tall-cell variant with extensive lymphocyte infiltration," American Journal of Surgical Pathology, vol. 20, no. 6, pp. 695-698, 1996.

[153] K. Segal, M. Ben-Bassat, and A. Avraham, "Hashimoto's thyroiditis and carcinoma of the thyroid gland," International Surgery, vol. 70, no. 3, pp. 205-209, 1985.

[154] C. Papewalis, M. Ehlers, and M. Schott, "Advances in cellular therapy for the treatment of thyroid cancer," Journal of Oncology, p. 179491, 2010.
[155] Z. Wang, G. Chakravarty, S. Kim et al., "Growth-inhibitory effects of human anti-insulin-like growth factor-1 receptor antibody (A12) in an orthotopic nude mouse model of anaplastic thyroid carcinoma," Clinical Cancer Research, vol. 12, no. 15, pp. 4755-4765, 2006.

[156] S. Kim, C. N. Prichard, M. N. Younes et al., "Cetuximab and irinotecan interact synergistically to inhibit the growth of orthotopic anaplastic thyroid carcinoma xenografts in nude mice," Clinical Cancer Research, vol. 12, no. 2, pp. 600-607, 2006.

[157] C. S. Mitsiades, N. S. Mitsiades, C. J. McMullan et al., "Inhibition of the insulin-like growth factor receptor-1 tyrosine kinase activity as a therapeutic strategy for multiple myeloma, other hematologic malignancies, and solid tumors," Cancer Cell, vol. 5, no. 3, pp. 221-230, 2004.

[158] M. Schott, J. Feldkamp, M. Klucken, G. Kobbe, W. A. Scherbaum, and J. Seissler, "Calcitonin-specific antitumor immunity in medullary thyroid carcinoma following dendritic cell vaccination," Cancer Immunology, Immunotherapy, vol. 51, no. 11-12, pp. 663-668, 2002.

[159] M. Schott, J. Seissler, M. Lettmann, V. Fouxon, W. A. Scherbaum, and J. Feldkamp, "Immunotherapy for medullary thyroid carcinoma by dendritic cell vaccination," Journal of Clinical Endocrinology and Metabolism, vol. 86, no. 10, pp. 4965-4969, 2001.

[160] C. Papewalis, B. Jacobs, M. Wuttke et al., "IFN- $\alpha$ skews monocytes into CD56-expressing dendritic cells with potent functional activities in vitro and in vivo," Journal of Immunology, vol. 180, no. 3, pp. 1462-1470, 2008.

[161] C. Papewalis, M. Wuttke, B. Jacobs et al., "Dendritic cell vaccination induces tumor epitope-specific Th1 immune response in medullary thyroid carcinoma," Hormone and Metabolic Research, vol. 40, no. 2, pp. 108-116, 2008. 


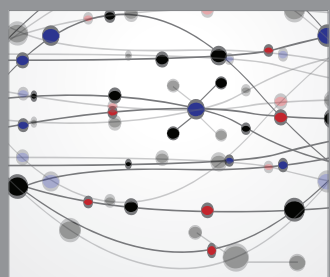

The Scientific World Journal
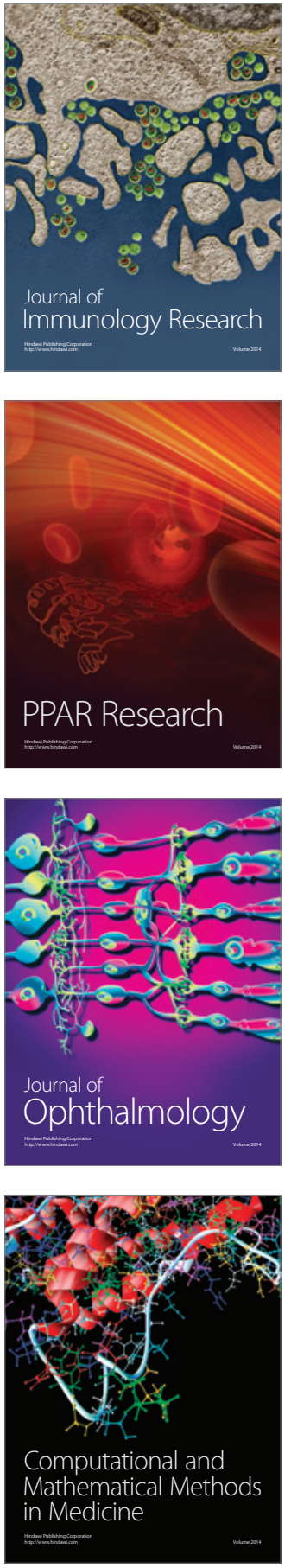

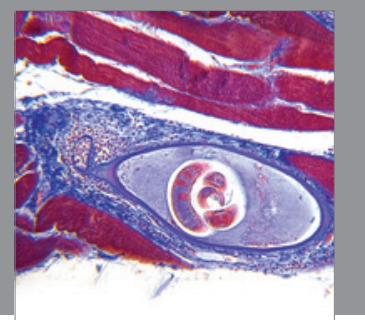

Gastroenterology

Research and Practice
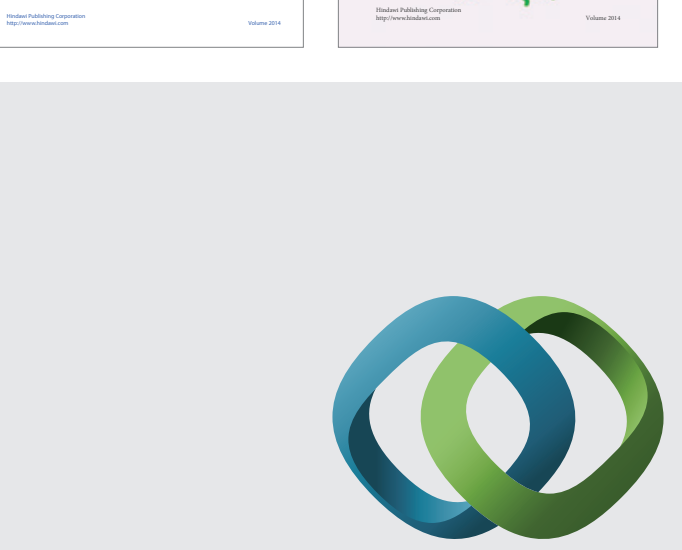

\section{Hindawi}

Submit your manuscripts at

http://www.hindawi.com
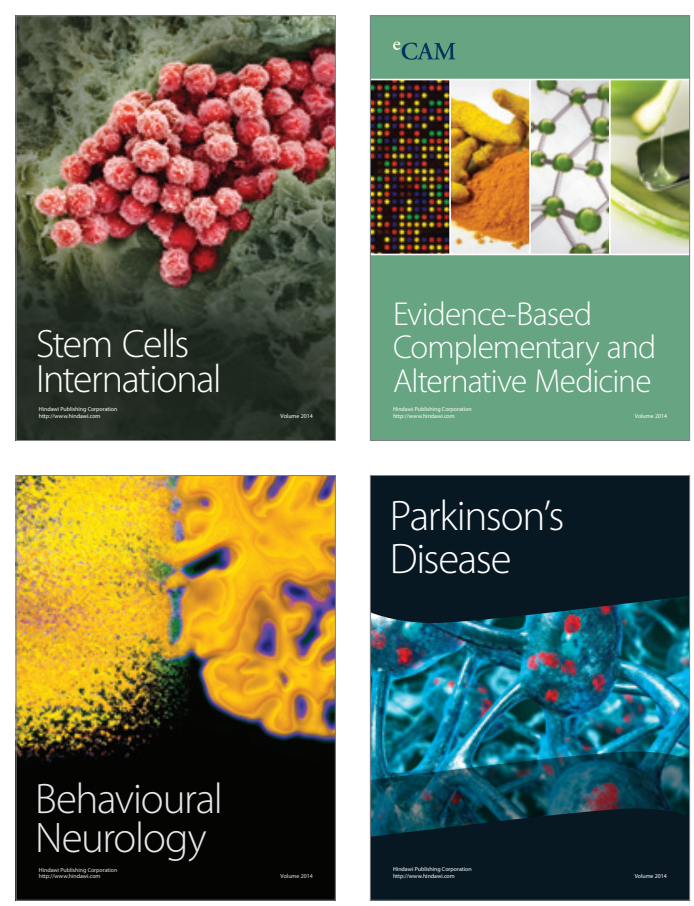

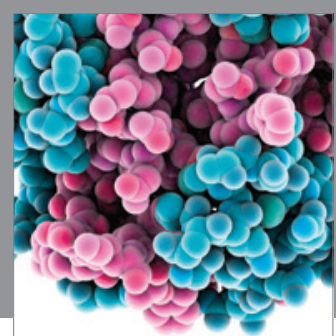

Journal of
Diabetes Research

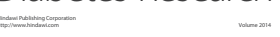

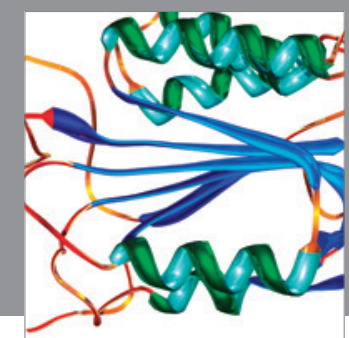

Disease Markers
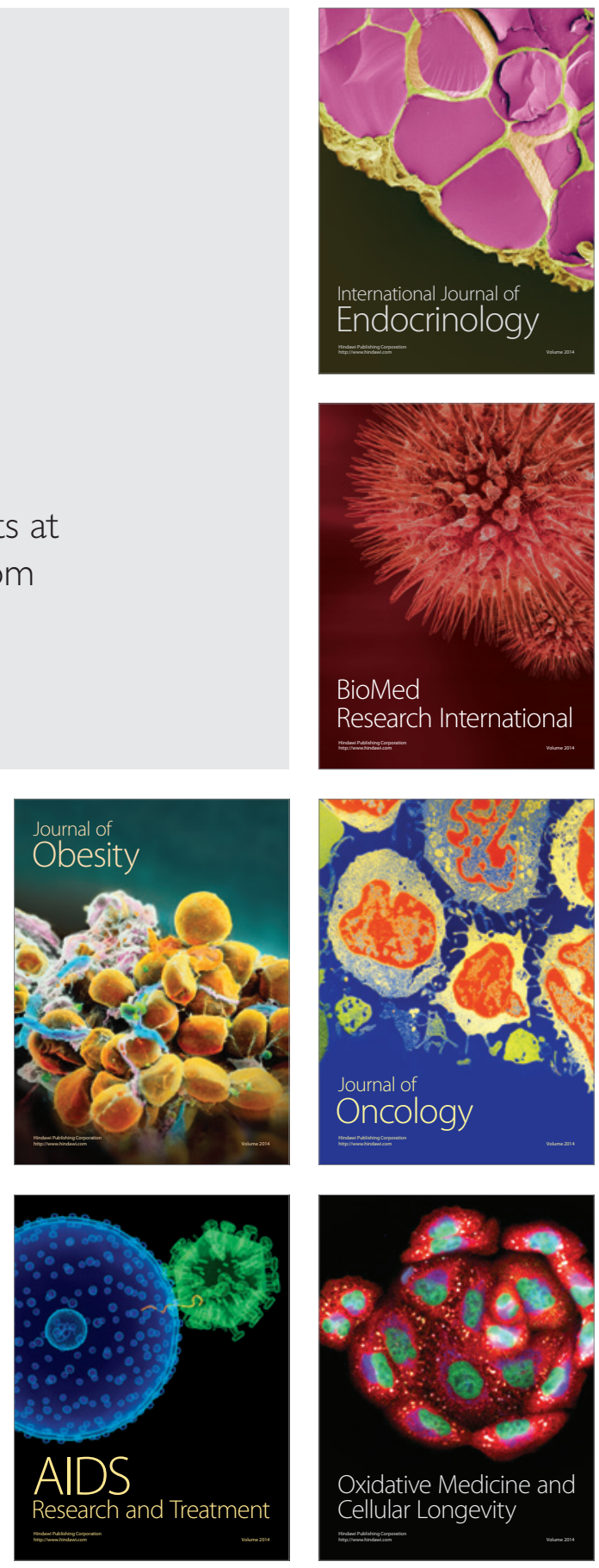